\title{
FORMAÇÃO DO PROFESSOR COMO AGENTE LETRADOR
}

\section{BORTONI-RICARDO, S. M.; MACHADO, V. R.; CASTANHEIRA, S. F. FORMAÇÃO DO PROFESSOR COMO AGENTE LETRADOR. SÃO PAULO: CONTEXTO, 2010. 192 P. ISBN 978- 85-7244-477-4}

\author{
Acir Mário Karwoski*
}

Junges e Karwoski (2002) publicaram um ensaio sem muita sustentação teórica nem prática (porém um ensaio provocador!) a respeito da necessária formação do professor das séries iniciais do ensino fundamental como agente letramentador, ou seja, aquele que promova de forma efetiva as práticas de leitura e de escrita tornando-as relevantes para a formação de cidadãos que por meio da língua (inter)agem na recepção e produção de textos, orais e escritos, de forma dialógica e contextualizada. Utilizei a expressão letramentadores, um neologismo, tentando mostrar a relação do termo com a noção de letramento(s). A obra Formação do professor como agente letrador chega em boa hora por suscitar a discussão e possibilitar reflexões a respeito das políticas e práticas de formação que ressaltem o trabalho do professor como agente de letramentos, especialmente nas séries iniciais de alfabetização.

A expressão letrador pode ter conotação com letras. Mas fica evidente, na obra Formação do professor como agente letrador, que se trata de o professor ser agente de letramento. Há muita discussão sendo realizada por aí a respeito do papel dos professores como agentes de letramentos, não apenas o letramento das letras, mas os multiletramentos (ROJO,

\footnotetext{
* Doutor em Letras - Estudos Linguísticos (UFPR). Professor da Universidade Federal do Triângulo Mineiro (UFTM). E-mail: < acirmario@letras.uftm.edu.br>.
} 
2009). Urge a necessidade de todos os professores envolvidos na Educação Básica serem responsáveis por trabalhar estratégias de leitura de forma a conduzir os alunos para a compreensão e construção de sentidos, não apenas os professores de língua portuguesa. A obra defende que todo professor é por definição um agente de letramento e que todo professor precisa familiarizar-se com metodologias voltadas para as estratégias facilitadoras da compreensão leitora. (p. 16).

A obra foi escrita por três autoras. A primeira, professora Stella Maris Bortoni-Ricardo, atua como docente e pesquisadora da área de letramento e formação de professores na Faculdade de Educação da Universidade de Brasília (UnB). É doutora na área de Linguística pela University of Lancaster com pós-doutorado em etnografia de sala de aula na University of Pensylvânia - USA). Possui diversas obras publicadas, destacando-se as da área de sociolinguística, tais como Nós cheguemu na escola, e agora? e $A$ sociolingüistica na sala de aula, ambas publicadas pela Parábola Editorial. A segunda autora, Veruska Ribeiro Machado, é mestre e doutora em educação, tendo atuado como docente nas séries finais do ensino fundamental e no ensino médio. Atuou também em cursos de graduação em Letras e Pedagogia. Atualmente é técnica em assuntos educacionais na Secretaria de Educação Superior (SESU) do MEC, investigando as concepções de leitura em avaliações de larga escala. A terceira autora, Salete Flôres Castanheira, é mestre em Educação pela Universidade de Brasília (UnB). Atua como professora no Departamento de Educação da Universidade Católica de Goiás (UCG). Realizou estudos em Psicologia Evolutiva e da Educação na Universidade de Santiago de Compostela - Espanha. Com essas credenciais, as autoras compartilham com o leitor suas experiências e investigações na área de educação, em especial a questão da leitura e o papel do professor nas atividades de compreensão de textos.

O livro organiza-se em doze capítulos articulados. O primeiro Por uma pedagogia da leitura -sendo introdutório, apresenta dados estatísticos a respeito do analfabetismo absoluto e o analfabetismo funcional no Brasil e discute de forma muito interessante e pertinente a formação de professores e a pedagogia da leitura. Segundo as autoras, o caráter sintetizador da leitura sob a responsabilidade apenas dos professores de língua portuguesa pode vir a explicar os baixos escores que os alunos obtêm nos sistemas de avaliação. Diante da importância 
do conhecimento multi e interdisciplinar a que um leitor deve recorrer no ato da leitura com vistas à compreensão, não bastam os conhecimentos linguísticos. É preciso que em todas as áreas do conhecimento o aluno construa habilidades de leitura como ferramenta de apreensão e de construção de sentidos. Para as autoras, os cursos de formação de professores negligenciam dimensões de natureza mais prática em benefício de uma suposta superioridade de conteúdos teóricos provenientes das ciências humanas. (p. 17).

O segundo capítulo - Matrizes de referência para a formação e o trabalho do professor como agente de letramento - apresenta as matrizes de habilidades de leitura e dos conhecimentos para avaliação do professor desde a educação infantil até o ensino médio. Traz uma exaustiva lista de verbos que precisa ser conhecida dos professores.

O terceiro capítulo - A mediação do professor na compreensão leitora discute a respeito dos protocolos de leitura e descreve um episódio de 60 minutos no qual uma professora e um aluno fazem a leitura de um texto retirado do livro didático de língua portuguesa no primeiro ano do ensino médio. Fica evidenciado que um bom trabalho pedagógico de andaimagem, na mediação da leitura, pode surtir efeitos muito positivos. (p. 26). Segundo as autoras, andaimagem é um conceito metafórico que se refere a um auxilio visivel ou audivel que um membro mais experiente de uma cultura pode dar a um aprendiz [...] em qualquer ambiente social onde tenham lugar processos de sociabilização. (p. 26). Na escola, professor e alunos são os agentes. Outro conceito discutido no capítulo é o das pistas de contextualização, ou seja, quaisquer sinais verbais on não verbais que, processados juntamente com [sic] elementos simbólicos gramaticais ou lexicais, servem para construir a base contextual para a interpretação localizada, afetando assim a forma como as mensagens são compreendidas. (p. 27). Segundo as autoras, todas as pistas de contextualização, inclusive as transmitidas por traços prosódicos, cinésicos e proxêmicos, associadas ao componente segmental dos enunciados, são a principal matéria-prima de que se constituem os andaimes. A microanálise das pistas de contextualização permite uma descrição pormenorizada do trabalho de andaimagem. $\mathrm{O}$ modelo de protocolos de leitura - com questionamentos e diálogos da professora e com o texto - permitiu para os alunos a construção de sentidos para o texto. 
O quarto capítulo - A leitura tutorial como estratégia de mediação do professor - apresenta o conceito de leitura tutorial, discute a respeito dos níveis de compreensão leitora e as estratégias de leitura. Segundo as autoras, o professor deve servir de guia do aluno na leitura dos diversos textos, atuando como seu tutor (dai o termo leitura tutorial), visto que a leitura deve ser compartilhada. (p. 60). Foi justificado pelas autoras que as estratégias apresentadas são apenas um exemplo de como podem ser desenvolvidas atividades anteriores, durante e depois da leitura.

Os três capítulos seguintes - quinto, sexto e sétimo - são exemplos de aplicação de propostas de leitura tutorial como estratégias de mediação a textos de diversos assuntos relacionados a várias disciplinas. São apresentadas e amplamente analisadas propostas de atividades de leitura com textos de Biologia, História e Geografia. Nestes capítulos, as autoras procuraram explorar textos de disciplinas pertencentes às séries finais do ensino fundamental e do ensino médio, com a intenção de mostrar aos professores que a leitura é uma atividade que requer habilidades especificas que devem ser desenvolvidas em todas as disciplinas, visto que cada conteúdo requer a mobilização de estratégias diferentes para que ocorra a compreensão. (p. 89).

No oitavo capítulo - Professor letrador nos anos iniciais do ensino fundamental: iniciação ao trabalho científico - há uma discussão a respeito da importância do letramento científico e da etnografia da prática desse letramento. As autoras apresentam os quatro níveis de letramento científico da Organização para Cooperação e Desenvolvimento Econômicos (OCDE): letramento científico nominal; letramento científico funcional; letramento mutidimensional em ciências e letramento científico. As práticas de letramento científico fundamentam-se na tese de que o conbecimento do senso comum, do cotidiano, permite aos alunos interagirem de forma significativa com as novas aprendizagens. Torna-se então necessário cuidar da qualidade dessa interação, utilizando estratégias de ensino que possam ajudá-los na aquisição dessas aprendizagens. (p. 93).

A exemplo da proposta de leitura tutorial, os quatro capítulos seguintes - nono, décimo, décimo primeiro e décimo segundo apresentam descrições e protocolos de práticas de sala de aula tendo como fundamento de reflexão a sociolinguística interacional. Segundo as autoras, a ação pedagógica fundamentada nos princípios da sociolinguística interacional e nas estratégias de andaimes contribui com o avanço da Zona de 
Desenvolvimento Proximal de Vigotsky por meio da intervenção e do monitoramento cuidadoso da professora, favorecendo a construção do conceito científico. (p. 143). Fica evidenciado, assim, que é possível alfabetizar letrando; mas essa prática exige do professor pensar e agir de forma interdisciplinar.

O livro encerra sem uma conclusão, apenas com as notas e bibliografia, dando-nos a impressão de que a conversa ainda continua. E precisa continuar. Conversa que precisa mostrar e convencer a muitos professores que não acreditam que podem ser agentes de letramento. A obra destina-se a estudantes em formação inicial (cursos de licenciatura), pedagogos e estudantes de magistério bem como professores em formação continuada de todas as áreas do conhecimento que atuam na Educação Básica. Os professores precisam conhecer as concepções de leitura e dominar as técnicas e protocolos de leitura, tais como as propostas de leitura tutorial e/ou de letramento científico, amplamente discutidas e muito bem apresentadas no livro.

Esta obra não propõe uma nova pedagogia de ensino; retoma de forma muito inteligente as concepções (socio)linguísticas e os pressupostos da etnografia de sala de aula para mostrar como é possível a um professor ser agente de letramento; discute de forma crítica e muito pertinente possíveis reformulações que podem vir a acontecer nas práticas de ensino de leitura pelos professores. Assim, a obra destina-se também aos agentes (re)formuladores de políticas públicas de educação.

Sem dúvida, todos os professores precisam estar familiarizados com as diversas estratégias facilitadoras da leitura, apresentadas e discutidas de forma inequívoca na obra. Os exemplos apresentados no livro são mostra de que é possível o professor ser agente de letramentos, não apenas o letramento das letras. Para que isso ocorra, é preciso, dentre outras ações, inserir estudos linguísticos, especialmente as teorias da leitura nos cursos de formação de professores. Sem dúvida, novas pesquisas em sala de aula e nos cursos de formação inicial e continuada de professores devem nos mostrar que é preciso investir na formação prática do professor como agente de multiletramentos no atual contexto das tecnologias de informação. 


\section{REFERÊNCIAS}

JUNGES, K. S.; KARWOSKI, A. M. Professores das séries iniciais do ensino fundamental: alfabetizadores ou letramentadores. Ensino \& Pesquisa, União da Vitória, PR, v. 1, n. 1, 2002, p. 101-104.

ROJO, R. Letramentos múltiplos, escola e inclusão social. São Paulo: Parábola Editorial, 2009.

Recebido em 25/08/10. Aprovado em 08/09/10. 